\title{
Cognitive impairment in patients with AIDS - prevalence and severity
}

\author{
This article was published in the following Dove Press journal: \\ HIVIAIDS - Research and Palliative Care \\ 29 January 2015 \\ Number of times this article has been viewed
}

\author{
Crystal C Watkins ${ }^{1,2}$ \\ Glenn J Treisman ${ }^{2}$ \\ 'The Memory Center in \\ Neuropsychiatry, Sheppard Pratt \\ Health System, ${ }^{2}$ Department of \\ Psychiatry and Behavioral Sciences, \\ The Johns Hopkins University School \\ of Medicine, Baltimore, MD, USA
}

Correspondence: Crystal C Watkins 600 North Wolfe Street, Phipps 300, Baltimore, MD 2/287-0005, USA

$\mathrm{Tel}+\mathrm{I} 4106140504$

Fax +I 4I0 6I43676

Email cwatkins@jhmi.edu
Abstract: The advent of highly active antiretroviral therapy has prolonged the life expectancy of HIV patients and decreased the number of adults who progress to AIDS and HIV-associated dementia. However, neurocognitive deficits remain a pronounced consequence of HIV/AIDS. HIV-1 infection targets the central nervous system in subcortical brain areas and leads to high rates of delirium, depression, opportunistic central nervous system infections, and dementia. Long-term HIV replication in the brain occurs in astrocytes and microglia, allowing the virus to hide from antiviral medication and later compromise neuronal function. The associated cognitive disturbance is linked to both viral activity and inflammatory and other mediators from these immune cells that lead to the damage associated with HIV-associated neurocognitive disorders, a general term given for these disturbances. We review the severity and prevalence of the neuropsychiatric complications of HIV including delirium, neurobehavioral impairments (depression), minor cognitive-motor dysfunction, and HIV-associated dementia.

Keywords: HIV, delirium, depression, HAND, dementia; HIV-associated neurocognitive disorder

\section{Introduction}

Combinations of antiretroviral drugs administered as highly active antiretroviral therapy (HAART) have decreased the HIV disease-related mortality and the severity of the illness. ${ }^{1}$ Now, more individuals manage HIV as a chronic disease given there is a decreased progression to AIDS and AIDS dementia. Despite these advances, neurocognitive disturbances from the HIV virus still persist as complex and clinically important problems.

With the prolonged life expectancy of patients to over age 50, age is also a factor in HIV-related cognitive disturbances. An estimated one of every four newly diagnosed HIV infections occurs in older adults. ${ }^{2-4}$ As patients age with HIV, HIV-associated neurocognitive disorders (HANDs) are known to cause significant morbidity and mortality and ultimately accelerate the aging process. Age is a known factor in the progression of HIV seropositivity, with a decreased incubation period from exposure to development of AIDS symptoms, ${ }^{5-7}$ decreased proliferation of T-lymphocytes, ${ }^{8,9}$ and significant risk of HANDs. ${ }^{7,10,11}$

HIV reproduces in microglia, the brain's immune cells, causing central nervous system (CNS) inflammation and progressive cognitive and behavioral changes. Although the clinical definitions have recently changed, ${ }^{12}$ HAND can range from asymptomatic neurocognitive impairment (ANI) to mild-motor neurocognitive disorder 
(MMND) with minor concentration and memory problems to HIV-associated dementia (HAD) with global cognitive impairment. ${ }^{13,14}$

Although somewhat controversial, ANI and MMND appear to be related to glial dysfunction and are diagnosed through neuropsychological tests, while HAD is a clinical diagnosis and may be the result of neuronal cell death.

In addition to age, major depression disorder (MDD) and HAND share common risk factors, including female sex, stage of HIV illness, comorbid illnesses such as Hepatitis B and $\mathrm{C}$, and injected drug use. The Research on Older Adults with HIV study collected self-report data from 2005 to 2006 on depressive symptomology from over 1000 HIV-positive men and women with HIV who had age 50 and older. Based on this study, there appears to be significant correlations with Depression Scale scores, higher disease burden, and cognitive impairment. ${ }^{15}$

Given that HIV-associated cognitive impairments span the scope of emotional changes, attention, executive dysfunction, and memory, we identify the various types of neuropsychiatric complications. We review the acute changes associated with altered mental status in delirium and the neurobehavioral impairments commonly attributed to major depressive disorder. We discuss the motor and memory dementia spectrum that includes ANI, mild-motor neurocognitive disorder, and HIV-dementia. Our goal is to provide an understanding of the prevalence, severity, diagnosis, and management of these conditions with the goal of helping clinicians identify and distinguish these clinical syndromes in AIDS patients.

\section{Primary psychiatric conditions associated with cognitive impairment Delirium}

\section{Prevalence and severity in HIV infection and AIDS}

The most common neuropsychiatric complication in hospitalized patients with AIDS is delirium. ${ }^{16,17}$ The overall prevalence of delirium in the general community is just $1 \%-2 \%$, but in the setting of general hospital admission this increases to $14 \%-24 \% .{ }^{18}$ However, the point prevalence of delirium in hospitalized AIDS patients is estimated to be between $30 \%$ and $40 \% .{ }^{19}$ There also appear to be higher rates of new cases of delirium at the time of HIV seroconversion. ${ }^{18,19}$ Given that delirium is often an acute condition that is present in hospitalized patients with a change in mental status, lifetime prevalence estimates are more difficult and not abundant in the literature. Most studies of AIDS-associated delirium were done in the mid-80s to the late 1990s during the pre-HAART era with a very few updated about the prevalence of AIDS-associated delirium since 2000.

Delirium in HIV patients presents with the same clinical features as in non-HIV-infected individuals and is characterized by a waxing and waning state of inability to attend, disorganized thinking or confusion, and fluctuations in the level of consciousness. Mood and memory changes are common and often have a diurnal variation. Aside from general risk factors such as comorbid medical problems, older age, multiple medications, and previous episodes of delirium, patients with HAD are the highest risk group to develop delirium. The waxing and waning nature of delirium can make it difficult to diagnose as the patients may present completely different mental states to different clinicians depending on when they are evaluated.

Delirium can be a severe problem in those dealing with advanced HIV infection and prolonged immunosuppression. ${ }^{20}$ Older studies estimated that $46 \%$ of institutionalized patients at skilled nursing facilities needed treatment for one or more occurrences of delirium. ${ }^{21}$ More recent studies have used delirium as a subtle indicator of higher morbidity and mortality in patients who have advanced to AIDS. ${ }^{22,23}$ Hospitalized patients with AIDS were also found to have increased mortality if delirium complicated their hospital course. $^{22}$ Age appears to be an independent variable, as delirium may also occur in children with AIDS. ${ }^{24}$

\section{Clinical symptoms and differential diagnosis}

Delirium may resemble other neuropsychiatric conditions and needs to be distinguished from other brain disorders, including MDD, AIDS mania, minor cognitive-motor disorder, HAD, and CNS infection. Delirium is often differentiated from other conditions because of a fluctuation in orientation and awareness, acute onset, and/or a connection to an underlying medical illness. The other disorders have a stable level of consciousness. Delirium can be complicated by an insidious illness or a rapid process. Alterations in circadian rhythms, mood state, and psychomotor speed may be observed. Delusions and hallucinations may also occur, which may be similar to those seen in dementia, depression, manic episodes, and even schizophrenia. Depression is commonly mistaken for delirium when a person is in a hypoactive state. Once the underlying insult is managed, the symptoms tend to resolve fairly rapidly. However, a $20 \%$ decrease in survival rate is associated with delayed or missed diagnosis in hospitalized patients. ${ }^{16}$ 
Determining the cause of delirium is critical to the management of HIV/AIDS patients. Prior to combination antiretroviral therapy, particular considerations in immunocompromised patients with HIV focused on atypical CNS and systemic bacterial infection with cytomegalovirus encephalopathy, mycobacterium avium, fungal infections, and hypoxia with Pneumocystis pneumonia. With the widespread use of HAART, and a fewer number of AIDS cases, delirium is more commonly associated with toxicity from polypharmacy, HIV-related cerebrovascular disease, and psychoactive drug withdrawal or intoxication. ${ }^{25}$ Due to the degree of cerebral involvement, HIV/AIDS patients are vulnerable to fluctuations in blood metabolites and hydration status. These variations, along with the HIV virus itself, may contribute to acute global brain dysfunction or encephalopathy, comparable to cytomegalovirus encephalopathy infection. ${ }^{16,26}$

To clarify the diagnosis, a detailed medical history and evaluation may need to be conducted at two different time points because of the waxing and waning nature of delirium. Several assessment tools have been studied in delirium and prove to be reliable in examining HIV/AIDS patients. These include the Folstein Mini-Mental Status Examination, the Delirium Rating Scale, and the Memorial Delirium Assessment Scale. ${ }^{27}$ Depending on the nature of the impairment, additional brain imaging may be warranted to look for signs of bleeding or infection, which may involve blood cultures, computed tomography, or magnetic resonance imaging (MRI). Although non-specific, electroencephalography (EEG) is being employed more often because it identifies electrical brain activity with a pattern different from that seen in seizure disorders. The diffuse cerebral dysfunction seen in delirium often causes slowing of EEG rhythms, and when present, may be helpful in supporting the diagnosis.

\section{Approaches to management and treatment}

Delirium in HIV/AIDS is treated in a similar manner to delirium in general medical conditions. The most effective initial step, whenever possible, is to pinpoint and remove the underlying, contributing factors. The next priority is to reorient the patient through environmental cues and initiate pharmacotherapy when indicated. The most studied antipsychotic treatment has been low-dose haloperidol. In double-blind, randomized control trials, open-label trials and others of oral and intramuscular administrations of the drug showed resolution of symptoms within 24 hours at lower doses with minimal side effects. ${ }^{27}$
Second-generation or atypical antipsychotics have been used in delirium, but are avoided as the first-line treatment because of adverse events in vulnerable populations and the elderly. ${ }^{28} \mathrm{~A}$ meta-analysis of prospective studies concluded that the first-generation antipsychotics haloperidol and chlorpromazine and the second-generation risperidone, quetiapine, and olanzapine were helpful in resolving delirium symptoms. ${ }^{29}$

Treatment with antipsychotic medication requires awareness of the higher susceptibility of patients with HIV to neuroleptic-induced extrapyramidal symptoms (EPS), even with exposure to drugs with low potential for inducing EPS. ${ }^{30,31}$ Patients with AIDS-related psychosis are more sensitive to EPS and respond to lower than standard doses of antipsychotics. ${ }^{25,32}$ If indicated, typical neuroleptic medications should be used at the lowest dosage for the briefest duration possible. Increased susceptibility to EPS has been particularly notable with the use of conventional neuroleptic medications and has limited the dosage used to treat patients. Extreme sensitivity to EPS is encountered in patients with HIV-dementia. ${ }^{32,33}$ Marked neuronal degeneration in the basal ganglia of patients with HIV may contribute to these findings because of the accompanying dopaminergic neuron destruction and/or alteration. ${ }^{34,35}$ Dyslipidemia and hyperglycemia are also potential side effects when using antipsychotics in the setting of antiretroviral therapy. ${ }^{36}$

To date, there have been a few randomized controlled trials in delirious patients with AIDS with documented efficacy of low-dose haloperidol and chlorpromazine. Benzodiazepines and anticholinergic medicines may contribute to delirium in some cases. These should be used minimally except when alcohol or benzodiazepine withdrawal is the precipitating factor. ${ }^{21}$ Lorazepam appeared to be ineffective in one study because of the associated and significant side effects; however, lorazepam was reported to be useful in cases of AIDS-associated psychosis with catatonia. ${ }^{28}$ However, in a systematic review, patients with AIDS treated with lorazepam developed confusion and were oversedated, resulting in discontinuation of the drug. ${ }^{26}$ Older case reports indicate that molindone (not currently manufactured) and ziprasidone are of benefit for HIV-associated psychosis and have minimal EPS. ${ }^{37}$

Atypical antipsychotics are generally preferred because of lower risk for EPS. Terminal delirium in AIDS, as in other terminal diseases, is more refractory to treatment. The use of physical restraints has grown out of favor as tends to worsen agitation and hospitalized patients are 
susceptible to pressure ulcers. In cases of severe agitation and physical violence, closely monitored restraints may be necessary when other alternatives are inadequate.

\section{Major depression}

\section{Prevalence and severity in HIV infection and AIDS}

Depression is a significant problem encountered by HIV and AIDS patients. MDD in HIV-infected patients has an estimated prevalence of $19 \%-43 \%$ depending on the region examined. ${ }^{38,39}$ The high prevalence may be due in part because of the populations at risk for HIV infection. Homosexual men and patients with substance use disorders tend to have elevated prevalence of MDD. A detailed review of 10 studies comparing HIV-positive and at-risk HIV-negative patients found that there were twice as many cases of MDD in patients infected with HIV compared to controls. $^{40}$

Lyketsos et al reported an association between depression and HIV infection as early as 1993 and speculated that MDD was a risk factor for developing HIV. ${ }^{41}$ Since that time, other studies have estimated depression rates between $15 \%$ and $40 \%$ in HIV-seropositive individuals depending on the geographic location and demographics of the group studied. ${ }^{42-44}$ The rates of MDD surpassed 50\% in outpatients with HIV pursuing mental health treatment. ${ }^{44,45}$ A sevenfold increase was found in the lifetime prevalence of affective illness, when screening patients for HIV, even without substance abuse issues. ${ }^{46}$

When examining severity of major depression of HIV/AIDS, most of the studies focus on the association of mood disorders with higher rates of disease transmission, lower rates of compliance, and psychological distress from the disease. Major depression makes individuals more susceptible to contracting HIV and AIDS because of its effect on behavior. Depression factors into HIV risk since it often impacts insight and judgment in decision-making and may exacerbate substance abuse. ${ }^{42,47,48}$ In this way, the vulnerability from MDD has been termed to be "a vector of HIV transmission" by some experts in the field. ${ }^{48,49}$ MDD not only serves as a risk for perpetuation of the HIV epidemic but also is a complication preventing effective treatment. ${ }^{50} \mathrm{MDD}$ has been associated with more rapid HIV disease progression to AIDS and higher mortality rates. ${ }^{51,52}$

Acting through diverse biological mechanisms, the HIV virus influences the brain's immune system, and the increased inflammatory disease burden may lead to increased risk of depression and other mood and psychotic symptoms. AIDS patients with high viral loads have been recognized as a group with a high risk of psychological distress, ${ }^{50,53}$ and high prevalence rates of suicide have been reported among HIV-infected patients in general. ${ }^{36,54}$ The HIV virus in the CNS appears to directly impact subcortical areas of the brain that also affect mood, the stress response, and behavior. The stress on the immune system, injury to the brain's mood center, and social stigma of HIV infection collectively promote social isolation, behavioral changes, and impulsive behaviors. Some experimental studies support this therapy. The Multicenter AIDS Cohort Study showed that rates of depression increased 2.5-fold as CD4 cells declined to fewer than $200 / \mathrm{mm}^{3}$ just before patients developed AIDS ${ }^{53}$ suggesting that lower CD4 cell counts predict increased rates of depression. A decreased number of natural killer T-cells available to mount a cytokine response ${ }^{51}$ and diminished levels of CD4 cells were identified in depressed patients with HIV. ${ }^{47}$ Therefore, depression and HIV appear to share common mechanisms that contribute to an additive risk of contracting HIV/AIDS and susceptibility to MDD when both illnesses are present.

\section{Symptoms and differential diagnosis}

The diagnosis of MDD in the HIV/AIDS clinic is complicated by the high frequency of depressive symptoms that are associated with these other problems. Routine screening for depression in people with HIV can effectively identify cases. Both the Patient Health Questionnaire-9 and Patient Health Questionnaire-2 have been valid and reliable. ${ }^{55,56}$

Unlike the low mood, poor sleep, poor appetite, and changes in self-attitude described in classic major depression, HIV-infected patients with major depression often present to their primary care physician with multiple somatic symptoms, including headache and gastrointestinal disturbances. With this constellation of vague symptoms, it is necessary to distinguish MDD from normal sadness, delirium, substance withdrawal and/or intoxication, opportunistic CNS infection, and dementia. Physiological disturbances resulting from malnutrition, wasting syndromes, and medication side effects also need to be ruled out.

Depression was at one time termed "pseudo-dementia" because of its ability to mimic cognitive as well as behavioral impairment. Therefore, problems with executive functioning, apathy, short-term memory loss, inattention, and sometimes general confusion are symptoms of depression mistaken for dementia.

Given the burdens of HIV in the later stages resulting in AIDS, clinicians often focus on the medical comorbidities, and the depression symptoms may be overlooked. Opportunistic infections, including CNS lymphoma, 
Cryptococcal meningitis, and toxoplasmosis, are more prevalent in AIDS and present a challenge to individual management and treatment of depression. Neurosyphilis is rare but common in AIDS and has been a long-standing imitator of MDD and psychotic symptoms. Relapse use of cocaine and the subsequent withdrawal can trigger depression-like symptoms with activated confusion that may be mistaken for dementia.

Demoralization, feeling hopeless or sad after contracting HIV, or having difficulty coping with the stress from the illness, is one of the most common feelings in HIV/AIDS. Clinically, this experience is referred to as "an adjustment disorder". ${ }^{53}$ Given the overlap with depression symptoms, systematic criteria must be applied for HIV patients to distinguish between the demoralization in adjustment disorder and MDD. Over $50 \%$ of outpatients presenting to an urban HIV clinic with depressive complaints were found to have an adjustment disorder alone. ${ }^{57}$ Unlike MDD, demoralization does not usually involve a change in self-concept or cognitive deficits. Other issues that arise with demoralization include guilt over acquiring HIV, guilt over infecting others, and anger at the source of disease, at oneself, or at God. The diagnosis of HIV infection may lead to precipitous revelation of hidden sexual or drug abuse behavior, eliciting shame and self-loathing. The stigma of HIV may lead to rejection or abandonment by loved-ones, and shunning by wider society, making patients feel socially isolated. Despite the development of HAART, some patients become hopeless, turn out nihilistic and forgo HIV treatment, evolve into a depressed state, and ultimately need antidepressant treatment.

Several drugs used in patients with HIV have been reported to produce a major depressive episode. Interferon, metoclopramide, sulfonamides, and steroids are associated with inducing depression symptoms in healthy individuals in addition to those with HIV. Efavirenz, a nonnucleoside reverse transcriptase inhibitor, has been associated with depression symptoms in AIDS patients during the first 4 weeks of use ${ }^{58}$ while long-term use over a 3 -year or more period was associated with anxiety instead of depression..$^{59,60}$ The treatment of drug-related depression symptoms is to decrease or eliminate the medication. Sometimes, when the medication is essential for HIV/AIDS treatment, physicians start antidepressant therapy to manage the mood symptoms.

\section{Management}

Once identified as MDD and distinguished from other illnesses, the goal is early treatment. HIV-positive patients appear to respond to antidepressant treatment at a level comparable to depressed patients without HIV and those with other comorbid illnesses. ${ }^{45,61,62}$ While several studies in the HIV/AIDS population reported a potential benefit to the tricyclic antidepressant (TCA) class of antidepressants, to date there does not appear to be a response difference between any specific TCA, selective serotonin reuptake inhibitors, or any other class of antidepressants. With all depressed patients, nonadherence is the most common reason for ineffective drug treatment, and adverse effects are the most common reason for nonadherence. Because HIV-infected patients are likely to be more sensitive to side effects, antidepressants should be started at subtherapeutic dosage and raised slowly. Clomipramine and imipramine are thought to have anti-inflammatory and neuroprotective effects by modulating glial cell activation in the CNS. ${ }^{63,64}$ However, TCAs have anticholinergic and other adverse effects that may sometimes make them difficult to use in patients with AIDS. Open-label trials of fluoxetine, sertraline, and paroxetine in various stages of HIV illness reported response rates (including affective and somatic depressive symptoms) between $70 \%$ and $90 \%$, and all the medications were well tolerated. ${ }^{61,65,66}$ One double-blind, placebo-controlled study of fluoxetine found significant response. ${ }^{67}$ Other similarly designed trials in HIV-infected users of intravenous cocaine and opioids showed significant reduction in depressive symptoms with fluoxetine compared with placebo or other antidepressant medications. ${ }^{25,66,68}$ Supportive group psychotherapy and fluoxetine were found to be superior to placebo and group therapy for a population of homosexual or bisexual men with HIV, and patients with more severe symptoms tended to achieve greater benefits from medication. $^{50,69}$

The side effects of certain antidepressants can render them advantageous or disadvantageous in particular patients with HIV. For example, selective serotonin reuptake inhibitors are best avoided in patients with chronic diarrhea. Sedating antidepressants should be avoided in patients with weakness, lethargy, orthostasis, or other risks for falls. TCAs should be avoided with oral candidiasis because of the aggravating effect of dry mouth on thrush. In cases of anorexia or cachexia, antidepressants with appetite-stimulating effects are best selected.

An important issue is the interaction of antidepressants and HAART medications. Treatment with HAART was linked with significant improvement in symptoms of depression but did not necessarily have a causal relationship. ${ }^{50,61,70}$ HAART failure or medication nonadherence appears to be magnified in untreated depression. ${ }^{20}$ Although debated and little 
evidence indicates that antidepressants cause fluctuations in CD4 cell counts, ${ }^{71,72}$ some experts believe that medication compliance improves with antidepressant treatment. ${ }^{45,50}$

However, the clinical significance of some of these drug-drug interactions has not yet been clearly established and future studies may need to focus on potential dose adjustments in AIDS patients.

\section{Neurocognitive conditions associated with HIV Minor cognitive-motor disorder}

\section{Prevalence and severity}

The nature of HIV-related neurocognitive disorders has rapidly evolved with the widespread use of antiviral treatment. With the contributions of aging, immune reactivation, antiviral-induced mitochondrial toxicity, gut leakiness, and chronic inflammation, the characteristics of these conditions have become much more heterogeneous. Overall, these conditions have become less "subcortical" and have a more unpredictable course with worsening and improvement in some patients over time.

Mild neurocognitive disorder and "minor" cognitivemotor disorder are similar terms used for the early stages of a spectrum of "dementia" syndromes seen in HIV disease. Unlike HAD, a late-stage disorder that we will describe in more detail in the next section, MMND may present at the beginning of HIV disease. However, the symptoms are subtle or may be elusive. MMND resembles HIV-dementia because of memory loss, difficulty with executive functioning, decreased fine motor skills, and gait disturbance. These are usually isolated complaints and have a mild degree of impairment. MMND is now regarded as part of the spectrum of HAD. With changes in terminology, its description as "minor cognitive-motor disorder" in the literature had fallen out of use. ${ }^{13,14}$

MMND appears to occur frequently in AIDS patients with prevalence rates approaching 60\% in the AIDS population. ${ }^{73}$ Because the symptoms may be overlooked, the incidence and recurrence rates have been difficult to estimate, especially in the early stages. Current research is looking to whether MMND inevitably leads to HIV-dementia. The effect of HAART now confounds this question; data from earlier in the epidemic cannot be reasonably compared with the current data. Early studies suggest that some patients remain stable with mild cognitive and motor symptoms while others advance to dementia. ${ }^{74}$ There are not any current markers to predict long-term outcome of the disease.

\section{Differential diagnosis}

The motor symptoms in MMND, although not always detected, often present before the cognitive symptoms. HIV patients may notice a fine tremor, difficulty typing, or repeating fine movements. The gait disturbance in early MMND may be a slight shuffle when walking or a wobble when running. The motor involvement may be mistaken for Parkinson's or a drug-induced tremor. ${ }^{75-77}$ Clinical features that resemble Parkinson's disease occur frequently with HIV-dementia and are attributed to disruption of the dopamine pathway. ${ }^{78}$ The motor symptoms may be attributed to side effects of the HIV medications, and therefore MMND can be overlooked. The physical examination may reveal frontal release signs; abnormal eye movements; and the inability to perform rapid, alternating movements, all of which worsen as the disease progresses. ${ }^{73,79}$ Opportunistic infections, especially in AIDS, should be ruled out with brain imaging. The HIV virus targets the brain and may produce these symptoms. ${ }^{80,81}$ Neuropsychiatric testing is helpful because it can pick up the discrete signs of short-term memory loss, inattention, and difficulties with activities of daily living associated with MMND. With the initial diagnosis of AIDS, with little to no signs of cognitive problems, decreased psychomotor speed has become the primary predictor of whether patients progress to dementia within the next 2 years. ${ }^{73,79}$ Recently, the Montreal Cognitive Assessment examination, a valid and reliable screening test for early cognitive impairment in elderly patients, was able to detect mild cognitive problems in HIV-positive patients with self-reported cognitive problems. ${ }^{82}$ Over $50 \%$ of these patients actually had some minor deficits in their cognitive abilities, not noted on any other part of their physical or mental status examination. ${ }^{82}$ With decades between some of the investigations, newer measurements are needed to identify cognitive problems at the early stages of HIV and AIDS.

\section{Management}

No controlled treatment data are available specifically for MMND disorder. Psychostimulants also have been evaluated for treatment of fatigue, cognitive impairment, and depression in patients with HIV. Open-label trials report an $85 \%$ mood response rate in patients with HAD taking methylphenidate ${ }^{17}$ and a 95\% mood response rate in men with AIDS taking dextroamphetamine. ${ }^{66,83}$ A double-blind trial showed a significant response to dextroamphetamine compared with placebo in patients with AIDS and major depression, subthreshold major depression, or dysthymia. ${ }^{83}$ Double-blind comparisons 
of methylphenidate, pemoline, and placebo in patients with HIV (most with AIDS) found improvement in both depressive symptoms and fatigue. ${ }^{28}$

\section{HIV-associated neurocognitive disorders}

\section{Prevalence and severity}

HAND is an all-inclusive designation given to the spectrum of neurological conditions that cause cognitive impairment and result from the immune system's response to HIV infection and metabolic encephalopathy. Ranging from the least to the most severe, HAND may refer to mild neurocognitive disorder (MND), HIV encephalopathy, HAD, or AIDS dementia complex (ADC). For our purposes, we reviewed mild cognitive impairment when discussing MND. We will focus on AID-associated dementia and will review more severe impairment.

In 1986, HAD was reported in up to two-thirds of AIDS patients ${ }^{84}$ but it is less frequent now in patients receiving HAART. $\mathrm{HAD}$ became the explanation for severe cognitive impairment and dementia in persons younger than age $60 .{ }^{85}$ However, its frequency among patients with otherwise asymptomatic HIV infection or T-helper cell number more than 500 cells $/ \mathrm{mm}^{3}$ was probably less than $5 \%$ in a community sample. ${ }^{86}$ In the Multicenter AIDS Cohort Study, the incidence of HAD declined 50\% from 1990 to 1992 and 1996 to 1998, a period during which effective antiretroviral therapy was used..$^{86,87}$

With the widespread use of HAART in developing countries in the mid-1990s, there was a dramatic fall off in the rates of AIDS dementia ${ }^{88}$ with cases usually associated with specific risk factors including female sex, being elderly, higher HIV viral titers, lower socioeconomic group, substance abuse, and iron-deficiency anemia. In the post-HAART era, minor-motor neurocognitive disorder and depression are more predictive of severity of HIV-dementia later in the disease course. ${ }^{73,79,89}$ $\mathrm{HAD}$ is generally observed in seropositive individuals who have CD4 cells at an all-time level below 200/. $\mathrm{mm}^{3}$.

The overall incidence and prevalence rates of HIV-dementia in the post-HAART era vary greatly by geography, treatment, and risk factors studied, as well as whether patients are sampled in the community, a clinic, or a hospital. Studies from 1996 to 2002 in Italy estimate rates of cognitive impairment and dementia as $55 \%$ and $10 \%$, respectively. ${ }^{90}$ In the country of Georgia, an estimated $25 \%$ of HIV/AIDS patients have developed dementia from the disease..${ }^{91}$ Of the women in Puerto Rico who were determined to be "at risk" for development of dementia based on their HIV status, $49 \%$ had cognitive impairment and $29 \%$ had dementia. ${ }^{92}$ This is in contrast to what is observed in hospitalized HIV/AIDS patients in
Kenya, where dementia is rarely detected. ${ }^{93}$ The factors that contribute to the variance of prevalence and incidence rates, whether related to the disease, environment, or diagnostic tools used, require further investigation.

\section{Prevalence associated with HAART} and substance abuse

While much of the discussion of HAND is focused on the role of HAART therapy in reducing the number of new cases of HAND in AIDS, the prevalence rate of $50 \%$ has remained stable. ${ }^{14,94,95}$ With patients living longer on HAART, there is some concern that AIDS dementia prevalence will increase in association with the length of infection or with residual virus confined to the CNS. ${ }^{80,94}$ Newer studies now suggest that HAART regimens, with long-term use, may also generate cognitive impairment symptoms. ${ }^{80,96}$ The toxicity of HAART may create a reservoir that reduces the severity of opportunistic infections, but HAART has not changed the degree of microglial activation or neuroinflammation generated by the HIV virus. ${ }^{64}$ To date, HAART has been linked with inflammation in the temporal cortex and the hippocampus, thus suggesting an association with working memory. Prior to the HAART era, inflammation was mainly seen in the basal ganglia and linked to more motor symptoms. HAART is now linked to an increased production of brain lymphocytes that lead to a transient motor-cognitive disorder that looks like amyotrophic lateral sclerosis. ${ }^{97}$ In addition, there appears to be a synergistic effect of HIV and drug abuse on expression of major histocompatibility complex II and CD68 inflammatory markers, leading to increased adverse effect on the brain than either individual insult on its own. ${ }^{98}$ As one review points out, with the longevity of HIV-positive patients, we may not be able to fully understand the combined role of HAART, drug abuse, and HIV until older patients and patients in the post-HAART era undergo postmortem pathological evaluations. ${ }^{99}$ Therefore, more research is needed about the relationship of CNS inflammation to HAART therapy.

\section{Symptoms and differential diagnosis}

Understanding the mechanisms that contribute to HAD would help with better identification of the symptoms and clinical management. Although an active area of investigation, the prevailing theories involve infection of the virus in brain macrophages and activated microglia in the CNS. ${ }^{100,101}$ Neurons, astrocytes, and oligodendrocytes do not appear to be directly infected by the virus. A cascade of chemokines and cytokines mediated by activated microglia cells leads to cell 
death through decreased arborization of neurons. Therefore, the immune system involvement may explain the subtlety of the clinical symptoms and global progression of the dementia over a period of time.

At the early stages, the chief complaints in HAD are a combination of short-term memory impairment, low mood, and motor slowing. At the initial onset, like MND, the symptoms may seem to be mild, but involve some disruption of the normal daily routines of managing financial obligations, following directions, reading, remembering names and dates, and remembering appointments. These symptoms are often indistinguishable from other types of dementia, misinterpreted as lethargy or missed because the signs are below clinical detection. As symptoms become more profound, they involve multiple regions of the brain that control long-term memory, name and facial recognition, language expression and comprehension, and organization and management.

Like many neuropsychiatric complications of HIV and AIDS, HAD shares symptoms common to depression, anxiety, and psychotic disorders that may be confused with other brain illnesses. Major depression symptoms of low or irritable mood, loss of pleasure and enjoyment, changes in sleep, weight loss, and tearful episodes are prevalent in HAD. ${ }^{42}$ In place of sadness, patients may be apathetic, retreat from their usual interests, and become emotionally distant and socially withdrawn. Anxiety, either from frustration with memory loss or general restlessness, appears to be universal in dementia. A subset of patients may develop paranoid delusions, visual or auditory hallucinations, or mania-type symptoms that develop into a psychosis that requires prompt treatment.

With the changes in mood, cognition, and altered perception of reality, some believe HAD may be a contributing factor to suicide in AIDS patients. ${ }^{36} \mathrm{HAD}$ has also developed in the presence of milder immunosuppression. ${ }^{95,102,103}$ With this compilation of symptoms, HAD appears to quickly evolve into AIDS dementia complex and ultimately ends in death after 2 years of diagnosis. ${ }^{103}$

\section{Evaluation and management}

Cognitive screening tools have been recently reviewed. ${ }^{104-106}$ The Mini-Mental Status Examination is a well-known, fast, and easy screening tool for cognitive impairment in general, but appears to be less sensitive in HIV-dementias. ${ }^{104} \mathrm{~A}$ useful bedside screening tool, the Modified HIV Dementia Scale, has been shown to be the most specific and valid assessment tool that can be repeated on serial occasions to follow the trend of symptoms and evolution of the dementia in multiple population types. ${ }^{107,108}$ Newer studies show the Montreal
Assessment Scale (Montreal Cognitive Assessment) has an advantage in that it is free and evaluates multiple cognitive domains in one sitting. Scores of less than 26 indicate a referral for additional neuropsychological assessments for cognitive deficits. ${ }^{82,105}$ In the course of neuropsychiatric testing, patients with signs of dementia will often have difficulty on timed and repetitive activities, particularly the Grooved Pegboard assessment and the oral Trail Making B task. The next step is brain MRI to look for any reversible pathology that may argue against the diagnosis.

Typical findings on MRI in the HIV/AIDS population with HAD include significant white matter lesions as well as cortical and subcortical atrophies. ${ }^{109,110}$ These abnormalities may appear as discreet foci, as patchy regions of confluent involvement, or as diffuse parenchymal involvement. ${ }^{109,110}$ Partial improvement of MRI signal abnormalities, worsening of atrophy, and prominent white matter intensities have been summarized in reviews of individuals with HAD taking zidovudine. ${ }^{109}$ MRI also has been suggested to be of utility in monitoring HAD therapy with HAART. ${ }^{111}$

Various functional neuroimaging techniques such as positron emission tomography, single-photon emission computed tomography, and magnetic resonance spectroscopy have shown alterations in cerebral blood flow and metabolic patterns in the brains of individuals infected with HIV. ${ }^{12-114}$ Most of these studies were done in patients with dementia or other cognitive impairment, ${ }^{115}$ but other magnetic resonance spectroscopy investigations showed abnormalities in patients with no cognitive deficit. ${ }^{14,116,117}$ Increased brain activation on functional MRI during working memory was found in patients with early HIV cognitive disturbance. ${ }^{114}$ Further studies showed increased stimulation areas in the brain on functional MRI in HIV-positive patients that predated clinical signs or deficits on cognitive tests. ${ }^{118}$

\section{Treatment}

Controlled trials for HAD have been reviewed elsewhere. ${ }^{25,119,120}$ Intensification of antiretroviral therapy and associated control of viral load are associated with significantly lower risk for progression to HAD. Furthermore, HAART improves learning and memory in patients with HAD. ${ }^{99,121}$

Controversy exists regarding the duration of treatment and outcome of dementia. The long-term effect of HAART on the course of HAD remains undetermined, with some evidence of ongoing HIV-related cognitive damage despite more than 3 years of potent antiretroviral treatment. ${ }^{122}$ The only other controlled trial of antiretroviral drugs compared effective antiviral therapy with and without added 
high-dose abacavir, but the study did not detect further cognitive improvement. A newer study was able to show some improvements in neurocognitive function over the first year after initiating antiretroviral therapy, but only in neuroasymptomatic HIV-infected subjects. ${ }^{123}$

Antiretroviral agents with and without good CNS penetration, combined with HAART, appear to be effective in treating the virus in the CNS. ${ }^{124}$ Drugs that cross the blood-brain barrier and accumulate in the cerebrospinal fluid include abacavir, stavudine, and zidovudine (nucleoside reverse transcriptase inhibitors) and the nonnucleoside nevirapine. Despite these theoretical CNS considerations, there is little evidence suggesting an improved outcome for any particular antiretroviral regimen. However, the higher proportions of patients with HAD compared with other AIDS-defining illnesses ${ }^{103}$ suggest that HAART may not be as effective for treating HAD.

Various clinical trials have evaluated neuroprotective medications for HAD including nimodipine, antioxidants, platelet-activating factor antagonist, T-peptide, and memantine, but none were shown to be efficacious. ${ }^{84,125-127}$

Dopamine-enhancing agents, although assumed to be related to the movement disorder in HAD, do not appear to be effective treatments in adults, despite earlier success in pediatric patients with movement disorders and HIV. ${ }^{128,129}$ Stimulant medications tested in some HIV patients have demonstrated improvement in cognitive abilities, ${ }^{130}$ but others have noted apparent acceleration of HAD in conjunction with psychostimulant therapy. ${ }^{28,131}$ There have not been more recent reported clinical trials with dopamine agonists or stimulants.

Risperidone and clozapine have been described in case reports of HAD with psychosis. Treatment with these antipsychotic agents showed marked resolution of psychotic symptoms and fewer extrapyramidal motor symptoms. ${ }^{32,132,133}$

In summary, the best management for HAD is to provide an ideal HAART regimen, establish a good medication adherence plan, and rapidly manage any related symptoms.

\section{Conclusion}

Neuropsychiatric complications are highly prevalent in HIV/AIDS patients. The foundation for this area of research was laid decades ago. With the decreased incidence of AIDS and AIDS-related complications after the implementation of HAART, there appears to be less research in the neuropsychiatric impairments in AIDS and few new studies to help further expand the field. Given the growing population of individuals aging with HIV, there are still questions that need to be answered about the pathophysiology and progression of neurocognitive disorders in advanced HIV.
Although the percentage of AIDS patients with HANDs has been reduced, this is at significantly lower rate of decline than similar AIDS-defining illnesses. This observation suggests that CNS eradication of HIV is becoming more challenging with current antiretroviral regimens. It has been proposed that increasing resistance to HAART regimens may be linked to this possible evolution. ${ }^{95}$ In the Multicenter AIDS Cohort Study from 1990 to $1998,{ }^{86}$ the proportion of cases of HAD in individuals with CD4 cell markers between 201 cells $/ \mathrm{mm}^{3}$ and 350 cells $/ \mathrm{mm}^{3}$ was higher in the period of 1996-1998 compared with the early 1990s. This implies that screening for all HAND should be extended to individuals with CD4 cell counts less than 350 cells $/ \mathrm{mm}^{3} .{ }^{95}$ The extended survival that antiretroviral regimens have offered patients also may increase their vulnerability to developing dementia rather than dying secondary to other fulminate complications. ${ }^{95}$

As we make progress in the treatment of HIV/AIDS and the clinical symptoms evolve, more research will be needed on preventative measures to delay the progression of the CNS involvement and minimize the morbidity and mortality seen in HIV-associated neurocognitive disorders.

\section{Acknowledgments}

Thanks to Dr Amanda Brown and Dr Justin McArthur for their support in this research through the 5R25 80661Translational Research in NeuroAIDS Program. This work was supported in part by the Johns Hopkins University Mosaic Initiative Faculty Development Award to CCW and a grant from the Women's Hospital Foundation to the Neuropsychiatry Program at Sheppard Pratt Hospital.

\section{Disclosure}

The authors report no conflicts of interest in this work.

\section{References}

1. UNAIDS. 2013 UNAIDS Report on the Global AIDS Epidemic; 2013. Available form: http://www.unaids.org/en/media/unaids/ contentassets/documents/epidemiology/2013/gr2013/ UNAIDS_Global_Report_2013_en.pdf. Accessed May 27, 2013.

2. Center for Disease Control (CDC). HIV Surveillance Report: Diagnoses of HIV Infection and AIDS in the United States and Dependent Areas. Atlanta, GA: US Department of Health and Human Services, CDC; 2005 [online]. Atlanta, GA: US Department of Health and Human Services, CDC; 2011.

3. Simone MJ, Appelbaum J. HIV in older adults. Geriatrics. 2008;63(12):6-12.

4. Nguyen N, Holodniy M. HIV infection in the elderly. Clin Interv Aging 2008;3(3):453-472.

5. Zablotsky D, Kennedy M. Risk factors and HIV transmission to midlife and older women: knowledge, options, and the initiation of safer sexual practices. J Acquir Immune Defic Syndr. 2003;33(Suppl 2):S122-S130.

6. Butt AM, Nandwani R. Sexually transmitted diseases in HIV-1-infected patients. Lancet. 2001;357(9267):1533. 
7. McArthur JC, Sacktor N, Selnes O. Human immunodeficiency virusassociated dementia. Semin Neurol. 1999;19(2):129-150.

8. Justice AC, McGinnis KA, Atkinson JH, et al. Psychiatric and neurocognitive disorders among HIV-positive and negative veterans in care: Veterans Aging Cohort Five-Site Study. AIDS. 2004; 18(Suppl 1):S49-S59.

9. Goodkin K, Wilkie FL, Concha M, et al. Aging and neuro-AIDS conditions and the changing spectrum of HIV-1-associated morbidity and mortality. J Clin Epidemiol. 2001;54(Suppl 1):S35-S43.

10. Valcour V, Shikuma C, Shiramizu B, et al. Higher frequency of dementia in older HIV-1 individuals: the Hawaii Aging with HIV-1 Cohort. Neurology. 2004;63(5):822-827.

11. Janssen RS, St Louis ME, Satten GA, et al. HIV infection among patients in US acute care hospitals. Strategies for the counseling and testing of the hospital patients. The Hospital HIV Surveillance Group. $N$ Engl $J$ Med. 1992;327(7):445-452.

12. Antinori A, Arendt G, Becker JT, et al. Updated research nosology for HIV-associated neurocognitive disorders. Neurology. 2007;69(18):1789-1799.

13. HRSA. HIV-Associated Dementia and Other Neurocognitive Disorders. Guide for HIV/AIDS Clinical Care, 2014. Available from: http:// hab.hrsa.gov/deliverhivaidscare/2014guide.pdf. Accessed October 27, 2014.

14. Cross S, Onen N, Gase A, Overton ET, Ances BM. Identifying risk factors for $\mathrm{HIV}$-associated neurocognitive disorders using the international HIV dementia scale. J Neuroimmune Pharmacol. 2013;8(5):1114-1122

15. Havlik RJ, Brennan M, Karpiak SE. Comorbidities and depression in older adults with HIV. Sex Health. 2011;8(4):551-559.

16. Sonneville R, Ferrand H, Tubach F, et al. Neurological complications of HIV infection in critically ill patients: clinical features and outcomes. J Infect. 2011;62(4):301-308.

17. Fernandez F, Levy JK, Samley HR, et al. Effects of methylphenidate in HIV-related depression: a comparative trial with desipramine. Int J Psychiatry Med. 1995;25(1):53-67.

18. Inouye SK. Delirium in hospitalized older patients: recognition and risk factors. J Geriatr Psychiatry Neurol. 1998;11(Fall 3):118-125; discussion $157-158$

19. Perry S, Marotta RF. AIDS dementia: a review of the literature. Alzheimer Dis Assoc Disord. 1987;1(4):221-235.

20. Angelino AF, Treisman GJ. Issues in co-morbid severe mental illnesses in HIV infected individuals. Int Rev Psychiatry. 2008;20(1):95-101.

21. Uldall KK, Berghuis JP. Delirium in AIDS patients: recognition and medication factors. AIDS Patient Care STDS. 1997;11(6):435-441.

22. Uldall KK, Harris VL, Lalonde B. Outcomes associated with delirium in acutely hospitalized acquired immune deficiency syndrome patients. Compr Psychiatry. 2000;41(2):88-91.

23. Uldall KK, Ryan R, Berghuis JP, Harris VL. Association between delirium and death in AIDS patients. AIDS Patient Care STDS. 2000;14(2):95-100.

24. Hatherill S, Flisher A. Delirium in children with HIV/AIDS. J Child Neurol. 2009;24(7):879-883.

25. Hill L, Lee KC. Pharmacotherapy considerations in patients with HIV and psychiatric disorders: focus on antidepressants and antipsychotics. Ann Pharmacother. 2013;47(1):75-89.

26. Candy B, Jackson KC, Jones L, Leurent B, Tookman A, King M. Drug therapy for delirium in terminally ill adult patients. Cochrane Database Syst Rev. 2012;11:CD004770.

27. Breitbart W, Marotta R, Platt MM, et al. A double-blind trial of haloperidol, chlorpromazine, and lorazepam in the treatment of delirium in hospitalized AIDS patients. Am J Psychiatry. 1996;153(2):231-237.

28. Breitbart W, Rosenfeld B, Kaim M, Funesti-Esch J. A randomized, double-blind, placebo-controlled trial of psychostimulants for the treatment of fatigue in ambulatory patients with human immunodeficiency virus disease. Arch Intern Med. 2001;161(3):411-420.

29. Seitz DP, Gill SS, van Zyl LT. Antipsychotics in the treatment of delirium: a systematic review. J Clin Psychiatry. 2007;68(1):11-21.
30. Valcour V, Watters MR, Williams AE, Sacktor N, McMurtray A, Shikuma C. Aging exacerbates extrapyramidal motor signs in the era of highly active antiretroviral therapy. $J$ Neurovirol. 2008;14(5):362-367.

31. Kelly DV, Beique LC, Bowmer MI. Extrapyramidal symptoms with ritonavir/indinavir plus risperidone. Ann Pharmacother. 2002;36(5):827-830.

32. Dolder CR, Patterson TL, Jeste DV. HIV, psychosis and aging: past, present and future. AIDS. 2004;18(Suppl 1):S35-S42.

33. Fernandez F, Levy JK, Mansell PW. Management of delirium in terminally ill AIDS patients. Int J Psychiatry Med. 1989;19(2):165-172.

34. Itoh K, Mehraein P, Weis S. Neuronal damage of the substantia nigra in HIV-1 infected brains. Acta Neuropathol. 2000;99(4):376-384.

35. Ferrando SJ, Wapenyi K. Psychopharmacological treatment of patients with HIV and AIDS. Psychiatr Q. 2002;73(Spring 1):33-49.

36. Carrico AW, Johnson MO, Morin SF, et al. Correlates of suicidal ideation among HIV-positive persons. AIDS. 2007;21(9):1199-1203.

37. Leso L, Schwartz TL. Ziprasidone treatment of delirium. Psychosomatics. 2002;43(1):61-62.

38. Cysique LA, Deutsch R, Atkinson JH, et al. Incident major depression does not affect neuropsychological functioning in HIV-infected men. J Int Neuropsychol Soc. 2007;13(1):1-11.

39. Gibbie T, Hay M, Hutchison CW, Mijch A. Depression, social support and adherence to highly active antiretroviral therapy in people living with HIV/AIDS. Sex Health. 2007;4(4):227-232.

40. Ciesla JA, Roberts JE. Meta-analysis of the relationship between HIV infection and risk for depressive disorders. Am J Psychiatry. 2001;158(5):725-730.

41. Lyketsos CG, Hoover DR, Guccione M, et al. Depressive symptoms as predictors of medical outcomes in HIV infection. Multicenter AIDS Cohort Study. JAMA. 1993;270(21):2563-2567.

42. Watkins CC, Treisman GJ. Neuropsychiatric complications of aging with HIV. J Neurovirol. 2012;18(4):277-290.

43. Rabkin JG, Wagner GJ, McElhiney MC, Rabkin R, Lin SH. Testosterone versus fluoxetine for depression and fatigue in HIV/AIDS: a placebocontrolled trial. J Clin Psychopharmacol. 2004;24(4):379-385.

44. American Psychiatric Association. Diagnostic and Statistical Manual of Mental Disorders, 4th Edition - Text Revision (DSMIV-TR). Washington, DC: American Psychiatric Association; 2000.

45. Watkins CC, Pieper AA, Treisman GJ. Safety considerations in drug treatment of depression in HIV-positive patients: an updated review. Drug Saf. 2011;34(8):623-639.

46. Nakimuli-Mpungu E, Musisi S, Katabira E, Nachega J, Bass J. Prevalence and factors associated with depressive disorders in an HIV+ rural patient population in southern Uganda. J Affect Disord. 2011;135(1-3):160-167.

47. Sledjeski EM, Delahanty DL, Bogart LM. Incidence and impact of posttraumatic stress disorder and comorbid depression on adherence to HAART and CD4+ counts in people living with HIV. AIDS Patient Care STDS. 2005;19(11):728-736.

48. Tsai AC, Mimiaga MJ, Dilley JW, et al. Does effective depression treatment alone reduce secondary HIV transmission risk? Equivocal findings from a randomized controlled trial. AIDS Behav. 2013;17(8):2765-2772.

49. Treisman GJ, Angelino AF, Hutton HE. Psychiatric issues in the management of patients with HIV infection. JAMA. 2001;286(22):2857-2864

50. Himelhoch S, Brown $\mathrm{CH}$, Walkup J, et al. HIV patients with psychiatric disorders are less likely to discontinue HAART. AIDS. 2009;23(13):1735-1742.

51. Alciati A, Gallo L, Monforte AD, Brambilla F, Mellado C. Major depression-related immunological changes and combination antiretroviral therapy in HIV-seropositive patients. Hum Psychopharmacol. 2007;22(1):33-40.

52. Ickovics JR, Hamburger ME, Vlahov D, et al. Mortality, CD4 cell count decline, and depressive symptoms among HIV-seropositive women: longitudinal analysis from the HIV Epidemiology Research Study. JAMA. 2001;285(11):1466-1474. 
53. Lyketsos CG, Hoover DR, Guccione M, et al. Changes in depressive symptoms as AIDS develops. The Multicenter AIDS Cohort Study. Am J Psychiatry. 1996;153(11):1430-1437.

54. Sherr L, Harding R, Lampe F, et al. Clinical and behavioural aspects of aging with HIV infection. Psychol Health Med. 2009;14(3):273-279.

55. Mao Y, Ge X, Frank CL, et al. Disrupted in schizophrenia 1 regulates neuronal progenitor proliferation via modulation of GSK3beta/ beta-catenin signaling. Cell. 2009;136(6):1017-1031.

56. Hirshfield S, Wolitski RJ, Chiasson MA, Remien RH, Humberstone M, Wong T. Screening for depressive symptoms in an online sample of men who have sex with men. AIDS Care. 2008;20(8):904-910.

57. Lyketsos CG, Hanson A, Fishman M, McHugh PR, Treisman GJ. Screening for psychiatric morbidity in a medical outpatient clinic for HIV infection: the need for a psychiatric presence. Int $J$ Psychiatry Med. 1994;24(2):103-113.

58. Clifford DB, Evans S, Yang Y, et al. Impact of efavirenz on neuropsychological performance and symptoms in HIV-infected individuals. Ann Intern Med. 2005;143(10):714-721.

59. Journot V, Chene G, De Castro N, et al. Use of efavirenz is not associated with a higher risk of depressive disorders: a substudy of the randomized clinical trial ALIZE-ANRS 099. Clin Infect Dis. 2006;42(12):1790-1799.

60. Clifford DB, Evans S, Yang Y, Acosta EP, Ribaudo H, Gulick RM. Long-term impact of efavirenz on neuropsychological performance and symptoms in HIV-infected individuals (ACTG 5097s). HIV Clin Trials. 2009;10(6):343-355.

61. Ferrando SJ, Freyberg Z. Treatment of depression in HIV positive individuals: a critical review. Int Rev Psychiatry. 2008;20(1):61-71.

62. Akena D, Stein DJ, Joska J. Does screening HIV-positive individuals in Uganda for major depressive disorder improve case detection rates and antidepressant prescription? AIDS Behav. 2012;17(8):2802-2807.

63. Huang TL, Leu HS, Liu JW. Lymphocyte subsets and viral load in male AIDS patients with major depression: naturalistic study. Psychiatry Clin Neurosci. 2006;60(6):687-692.

64. Harezlak J, Buchthal S, Taylor M, et al. Persistence of HIV-associated cognitive impairment, inflammation, and neuronal injury in era of highly active antiretroviral treatment. AIDS. 2011;25(5):625-633.

65. Rabkin JG, Rabkin R, Harrison W, Wagner G. Effect of imipramine on mood and enumerative measures of immune status in depressed patients with HIV illness. Am J Psychiatry. 1994;151(4):516-523.

66. Rabkin JG, Rabkin R, Wagner G. Effects of fluoxetine on mood and immune status in depressed patients with HIV illness. J Clin Psychiatry. 1994;55(3):92-97.

67. Rabkin JG, Wagner GJ, Rabkin R. Fluoxetine treatment for depression in patients with HIV and AIDS: a randomized, placebo-controlled trial. Am J Psychiatry. 1999;156(1):101-107.

68. Tsai AC, Karasic DH, Hammer GP, et al. Directly observed antidepressant medication treatment and HIV outcomes among homeless and marginally housed HIV-positive adults: a randomized controlled trial. Am J Public Health. 2012;103(2):308-315.

69. Zisook S, Peterkin J, Goggin KJ, Sledge P, Atkinson JH, Grant I. Treatment of major depression in HIV-seropositive men. HIV Neurobehavioral Research Center Group. J Clin Psychiatry. 1998;59(5):217-224.

70. Tsai AC, Weiser SD, Petersen ML, Ragland K, Kushel MB, Bangsberg DR. A marginal structural model to estimate the causal effect of antidepressant medication treatment on viral suppression among homeless and marginally housed persons with HIV. Arch Gen Psychiatry. 2010;67(12):1282-1290.

71. Kumar V, Encinosa W. Effects of antidepressant treatment on antiretroviral regimen adherence among depressed HIV-infected patients. Psychiatr Q. 2009;80(3):131-141.

72. Schroecksnadel K, Sarcletti M, Winkler C, et al. Quality of life and immune activation in patients with HIV-infection. Brain Behav Immun. 2008;22(6):881-889.

73. Sevigny JJ, Albert SM, McDermott MP, et al. Evaluation of HIV RNA and markers of immune activation as predictors of HIV-associated dementia. Neurology. 2004;63(11):2084-2090.
74. Price RW, Brew B, Sidtis J, Rosenblum M, Scheck AC, Cleary P. The brain in AIDS: central nervous system HIV-1 infection and AIDS dementia complex. Science. 1988;239(4840):586-592.

75. Koutsilieri E, Sopper S, Scheller C, Ter Meulen V, Riederer P. Parkinsonism in HIV dementia. J Neural Transm. 2002;109(5-6):767-775.

76. Koutsilieri E, Sopper S, Scheller C, Ter Meulen V, Riederer P. Involvement of dopamine in the progression of AIDS dementia complex. J Neural Transm. 2002;109(3):399-410.

77. Mirsattari SM, Power C, Nath A. Parkinsonism with HIV infection. Mov Disord. 1998;13(4):684-689.

78. Hriso E, Kuhn T, Masdeu JC, Grundman M. Extrapyramidal symptoms due to dopamine-blocking agents in patients with AIDS encephalopathy. Am J Psychiatry. 1991;148(11):1558-1561.

79. Dunlop O, Bjørklund R, Bruun JN, et al. Early psychomotor slowing predicts the development of HIV dementia and autopsy-verified HIV encephalitis. Acta Neurol Scand. 2002;105(4):270-275.

80. Letendre SL, Ellis RJ, Ances BM, McCutchan JA. Neurologic complications of HIV disease and their treatment. Top HIV Med. 2007;18(2):45-55.

81. Levine AJ, Hinkin CH, Ando K, et al. An exploratory study of long-term neurocognitive outcomes following recovery from opportunistic brain infections in HIV+ adults. $J$ Clin Exp Neuropsychol. 2008;30(7):836-843.

82. Koski L, Brouillette MJ, Lalonde R, et al. Computerized testing augments pencil-and-paper tasks in measuring HIV-associated mild cognitive impairment (*). HIV Med. 2011;12(8):472-480.

83. Wagner GJ, Rabkin R. Effects of dextroamphetamine on depression and fatigue in men with HIV: a double-blind, placebo-controlled trial. J Clin Psychiatry. 2000;61(6):436-440.

84. Navia BA, Price RW. The acquired immunodeficiency syndrome dementia complex as the presenting or sole manifestation of human immunodeficiency virus infection. Arch Neurol. 1987;44(1):65-69.

85. McArthur JC, Hoover DR, Bacellar H, et al. Dementia in AIDS patients: incidence and risk factors. Multicenter AIDS Cohort Study. Neurology. 1993;43(11):2245-2252.

86. Sacktor N, McDermott MP, Marder K, et al. HIV-associated cognitive impairment before and after the advent of combination therapy. J Neurovirol. 2002;8(2):136-142.

87. Sacktor N. The epidemiology of human immunodeficiency virusassociated neurological disease in the era of highly active antiretroviral therapy. J Neurovirol. 2002;8(Suppl 2):115-121.

88. Bhaskaran K, Mussini C, Antinori A, et al. Changes in the incidence and predictors of human immunodeficiency virus-associated dementia in the era of highly active antiretroviral therapy. Ann Neurol. 2008;63(2):213-221.

89. Stern Y, McDermott MP, Albert S, et al. Factors associated with incident human immunodeficiency virus-dementia. Arch Neurol. 2001;58(3):473-479.

90. Tozzi V, Balestra P, Lorenzini P, et al. Prevalence and risk factors for human immunodeficiency virus-associated neurocognitive impairment, 1996 to 2002: results from an urban observational cohort. J Neurovirol. 2005;11(3):265-273.

91. Bolokadze N, Gabunia P, Ezugbaia M, Gatserelia L, Khechiashvili G. Neurological complications in patients with HIV/AIDS. Georgian Med News. 2008;(165):34-38.

92. Wojna V, Skolasky RL, Hechavarría R, et al. Prevalence of human immunodeficiency virus-associated cognitive impairment in a group of Hispanic women at risk for neurological impairment. J Neurovirol. 2006;12(5):356-364.

93. Jowi JO, Mativo PM, Musoke SS. Clinical and laboratory characteristics of hospitalised patients with neurological manifestations of HIV/AIDS at the Nairobi hospital. East Afr Med J. 2007;84(2):67-76.

94. Heaton RK, Clifford DB, Franklin DR Jr, et al. HIV-associated neurocognitive disorders persist in the era of potent antiretroviral therapy: CHARTER Study. Neurology. 2010;75(23):2087-2096.

95. McArthur JC, Steiner J, Sacktor N, Nath A. Human immunodeficiency virus-associated neurocognitive disorders: Mind the gap. Ann Neurol. 2010;67(6):699-714. 
96. Finzi D, Hermankova M, Pierson T, et al. Identification of a reservoir for HIV-1 in patients on highly active antiretroviral therapy. Science. 1997;278(5341):1295-1300.

97. Anthony IC, Ramage SN, Carnie FW, Simmonds P, Bell JE. Influence of HAART on HIV-related CNS disease and neuroinflammation. J Neuropathol Exp Neurol. 2005;64(6):529-536.

98. Anthony IC, Ramage SN, Carnie FW, Simmonds P, Bell JE. Does drug abuse alter microglial phenotype and cell turnover in the context of advancing HIV infection? Neuropathol Appl Neurobiol. 2005;31(3):325-338.

99. Cysique LA, Brew BJ. Neuropsychological functioning and antiretroviral treatment in HIV/AIDS: a review. Neuropsychol Rev. 2009;19(2):169-185.

100. Gonzalez-Scarano F, Martin-Garcia J. The neuropathogenesis of AIDS. Nat Rev Immunol. 2005;5(1):69-81.

101. Kaul M. HIV's double strike at the brain: neuronal toxicity and compromised neurogenesis. Front Biosci. 2008;13:2484-2494.

102. Heaton RK, Franklin DR, Ellis RJ, et al. HIV-associated neurocognitive disorders before and during the era of combination antiretroviral therapy: differences in rates, nature, and predictors. $J$ Neurovirol. 2010;17(1):3-16.

103. Dore GJ, Correll PK, Li Y, Kaldor JM, Cooper DA, Brew BJ. Changes to AIDS dementia complex in the era of highly active antiretroviral therapy. AIDS. 1999;13(10):1249-1253.

104. Skinner S, Adewale AJ, DeBlock L, Gill MJ, Power C. Neurocognitive screening tools in HIV/AIDS: comparative performance among patients exposed to antiretroviral therapy. HIV Med. 2009;10(4):246-252.

105. Hasbun R, Eraso J, Ramireddy S, et al. Screening for neurocognitive impairment in HIV individuals: the utility of the Montreal Cognitive Assessment Test. J AIDS Clin Res. 2013;3(10):186.

106. Gandhi NS, Moxley RT, Creighton J, et al. Comparison of scales to evaluate the progression of HIV-associated neurocognitive disorder. HIV Ther. 2010;4(3):371-379.

107. Davis HF, Skolasky RL Jr, Selnes OA, Burgess DM, McArthur JC. Assessing HIV-associated dementia: modified HIV dementia scale versus the Grooved Pegboard. AIDS Read. 2002;12(1):29-31, 38.

108. Oshinaike OO, Akinbami AA, Ojo OO, Ojini IF, Okubadejo UN, Danesi AM. Comparison of the Minimental State Examination Scale and the International HIV Dementia Scale in Assessing Cognitive Function in Nigerian HIV Patients on Antiretroviral Therapy. AIDS Res Treat. 2012;2012:581531.

109. Descamps M, Hyare H, Zerizer I, J A Ger H. Neuroimaging of CNS involvement in HIV. J HIV Ther. 2008;13(3):48-54.

110. Roc AC, Ances BM, Chawla S, et al. Detection of human immunodeficiency virus induced inflammation and oxidative stress in lenticular nuclei with magnetic resonance spectroscopy despite antiretroviral therapy. Arch Neurol. 2007;64(9):1249-1257.

111. Thurnher MM, Schindler EG, Thurnher SA, Pernerstorfer-Schon H, Kleibl-Popov C, Rieger A. Highly active antiretroviral therapy for patients with AIDS dementia complex: effect on MR imaging findings and clinical course. AJNR Am J Neuroradiol. 2000;21(4):670-678.

112. Descamps M, Hyare H, Stebbing J, Winston A. Magnetic resonance imaging and spectroscopy of the brain in HIV disease. J HIV Ther. 2008;13(3):55-58.

113. Sundgren PC, Dong Q, Gomez-Hassan D, Mukherji SK, Maly P, Welsh R. Diffusion tensor imaging of the brain: review of clinical applications. Neuroradiology. 2004;46(5):339-350.

114. Chang L, Lee PL, Yiannoutsos CT, et al. A multicenter in vivo protonMRS study of HIV-associated dementia and its relationship to age. Neuroimage. 2004;23(4):1336-1347.

115. Mohamed MA, Barker PB, Skolasky RL, et al. Brain metabolism and cognitive impairment in HIV infection: a 3-T magnetic resonance spectroscopy study. Magn Reson Imaging. 2010;28(9):1251-1257.
116. Yiannoutsos CT, Ernst T, Chang L, et al. Regional patterns of brain metabolites in AIDS dementia complex. Neuroimage. 2004;23(3):928-935.

117. Meyerhoff DJ, MacKay S, Bachman L, et al. Reduced brain $\mathrm{N}$-acetylaspartate suggests neuronal loss in cognitively impaired human immunodeficiency virus-seropositive individuals: in vivo 1H magnetic resonance spectroscopic imaging. Neurology. 1993; 43(3 pt 1):509-515.

118. Ernst T, Chang L, Jovicich J, Ames N, Arnold S. Abnormal brain activation on functional MRI in cognitively asymptomatic HIV patients. Neurology. 2002;59(9):1343-1349.

119. Schifitto G, Kieburtz K, McDermott MP, et al. Clinical trials in HIV-associated cognitive impairment: cognitive and functional outcomes. Neurology. 2001;56(3):415-418.

120. Uthman OA, Abdulmalik JO. Adjunctive therapies for AIDS dementia complex. Cochrane Database Syst Rev. 2008;(3):CD006496.

121. Robinson-Papp J, Elliott KJ, Simpson DM. HIV-related neurocognitive impairment in the HAART era. Curr HIV/AIDS Rep. 2009;6(3):146-152.

122. Tozzi V, Balestra P, Serraino D, et al. Neurocognitive impairment and survival in a cohort of HIV-infected patients treated with HAART. AIDS Res Hum Retroviruses. 2005;21(8):706-713.

123. Winston A, Puls R, Kerr SJ, et al. Dynamics of cognitive change in HIV-infected individuals commencing three different initial antiretroviral regimens: a randomized, controlled study. HIV Med. 2011;13(4):245-251.

124. Rourke SB, Halman MH, Bassel C. Neurocognitive complaints in HIV-infection and their relationship to depressive symptoms and neuropsychological functioning. J Clin Exp Neuropsychol. 1999;21(6):737-756.

125. Heseltine PN, Goodkin K, Atkinson JH, et al. Randomized double-blind placebo-controlled trial of peptide $\mathrm{T}$ for HIV-associated cognitive impairment. Arch Neurol. 1998;55(1):41-51.

126. Consortium D. A randomized, double-blind, placebo-controlled trial of deprenyl and thioctic acid in human immunodeficiency virus-associated cognitive impairment. Dana Consortium on the Therapy of HIV Dementia and Related Cognitive Disorders. Neurology. 1998;50(3):645-651.

127. Schifitto G, Navia BA, Yiannoutsos CT, et al; Adult AIDS Clinical Trial Group (ACTG) 301, 700 Teams, HIV MRS Consortium. Memantine and HIV-associated cognitive impairment: a neuropsychological and proton magnetic resonance spectroscopy study. AIDS. 2007;21(14):1877-1886.

128. Kieburtz KD, Giang DW, Schiffer RB, Vakil N. Abnormal vitamin B12 metabolism in human immunodeficiency virus infection. Association with neurological dysfunction. Arch Neurol. 1991;48(3):312-314.

129. Mintz M, Tardieu M, Hoyt L, McSherry G, Mendelson J, Oleske J. Levodopa therapy improves motor function in HIV-infected children with extrapyramidal syndromes. Neurology. 1996;47(6): 1583-1585.

130. Hinkin CH, Castellon SA, Hardy DJ, Farinpour R, Newton T, Singer E. Methylphenidate improves HIV-1-associated cognitive slowing. J Neuropsychiatry Clin Neurosci. 2001;13(Spring 2):248-254.

131. Czub S, Koutsilieri E, Sopper S, et al. Enhancement of central nervous system pathology in early simian immunodeficiency virus infection by dopaminergic drugs. Acta Neuropathol. 2001;101(2): 85-91.

132. Dettling M, Muller-Oerlinghausen B, Britsch P. Clozapine treatment of HIV-associated psychosis - too much bone marrow toxicity? Pharmacopsychiatry. 1998;31(4):156-157.

133. Zilikis N, Nimatoudis I, Kiosses V, Ierodiakonou C. Treatment with risperidone of an acute psychotic episode in a patient with AIDS. Gen Hosp Psychiatry. 1998;20(6):384-385. 
HIV/AIDS - Research and Palliative Care

Dovepress

\section{Publish your work in this journal}

HIV/AIDS - Research and Palliative Care is an international, peerreviewed open-access journal focusing on advances in research in HIV, its clinical progression and management options including antivira treatment, palliative care and public healthcare policies to control viral spread. The journal welcomes original research, basic science, clinical \& epidemiological studies, reviews \& evaluations, expert opinion \& commentary, case reports \& extended reports. The manuscript management system is completely online and includes a very quick and fair peer-review system. Visit http://www.dovepress.com/ testimonials.php to read real quotes from published authors.

Submit your manuscript here: http://www.dovepress.com/hivaids---research-and-palliative-care-journal 